Pure Appl. Chem., Vol. 76, No. 5, pp. 973-981, 2004.

(C) 2004 IUPAC

\title{
NO donors: Focus on furoxan derivatives*
}

\author{
A. Gasco ${ }^{1, \ddagger}$, R. Fruttero ${ }^{1}$, G. Sorba ${ }^{2}$, A. Di Stilo ${ }^{1}$, and R. Calvino ${ }^{1}$ \\ ${ }^{1}$ Dipartimento di Scienza e Tecnologia del Farmaco, Università degli Studi di \\ Torino, via P. Giuria 9, I-10125 Torino, Italy; ${ }^{2}$ Dipartimento di Scienze Chimiche, \\ Alimentari, Farmaceutiche e Farmacologiche, Università degli Studi del Piemonte \\ Orientale, via Bovio 6, I-28100 Novara, Italy
}

\begin{abstract}
The article focuses attention on furoxan derivatives (1,2,5-oxadiazole 2-oxides) as NO donors. Possible mechanisms for NO release from these products in physiological solution and in segments of rabbit femoral artery are briefly considered. The in vitro antiaggregatory activities and the in vitro and in vivo vasodilating properties of a number of furoxans are examined with particular reference to involvement of NO in these actions. The use of the furoxan system to design new NO donor/drug hybrids is discussed in connection with the problem of the balance between NO- and drug-dependent activities of the resulting structures. Whether other biological activities (as yet, little studied) of furoxans, such as their antiparasite, antimicrobial, and antitumoral effects, are NO-dependent, is a matter still to be explored.
\end{abstract}

\section{INTRODUCTION}

Nitric oxide, the nitrogen monoxide radical $\mathrm{NO}^{\bullet}$, is a physiological messenger that is almost ubiquitous in human tissues. It is synthesized from L-arginine under the action of a family of enzymes called NO synthase (NOS). It directly diffuses to the target or is transported there as metal complex or nitrosothiol. Nitric oxide displays diverse potent physiological actions [1]. As regards the cardiovascular system, it helps to maintain micro- and macro-vascular homeostasis through several mechanisms including vasodilation, inhibition of platelet aggregation, and modulation of platelet and leukocyte adhesion to the endothelium (Fig. 1). In the central nervous system, it plays roles in learning and memory formation. In the peripheral nervous system, it regulates a number of gastrointestinal, genitourinary, and respiratory functions as neurotransmitter at the endings of nonadrenergic, noncholinergic nerves (NANC). Nitric oxide is produced in all these compartments in very low concentrations (nM) and triggers all these effects by a common mechanism: activation of the soluble guanylate cyclase (sGC). It is also one of the final effectors of the immune response (Fig. 1). High concentrations $(\mu \mathrm{M})$ are produced in particular by macrophages. It diffuses into the parasite cell, where it exerts cytotoxic effects through a number of mechanisms, including formation of reactive nitrogen species (RNS) and inhibition of enzymes.

\footnotetext{
*Lecture presented at the Polish-Austrian-German-Hungarian-Italian Joint Meeting on Medicinal Chemistry, Kraków, Poland, 15-18 October 2003. Other presentations are published in this issue, pp. 907-1032.

${ }^{\ddagger}$ Corresponding author
} 


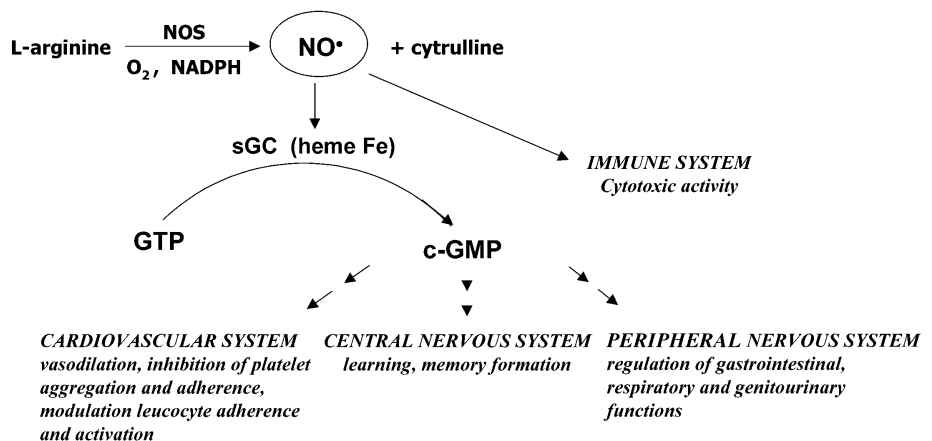

Fig. 1 Biosynthesis and biological actions of nitric oxide.

\section{NO DONORS}

There is much interest today in drugs related to nitric oxide, especially in structures able to release NO (Fig. 2). These products are collectively called NO donors [2]. In this connection, the term NO is frequently used in the broad sense, as a "family name" embracing not only $\mathrm{NO}^{\bullet}$, but also its two redox forms, nitroxyl (HNO) and nitrosonium ion $\left(\mathrm{NO}^{+}\right)$. These two species play important roles in the signalling system related to $\mathrm{NO}^{\bullet}[3]$.

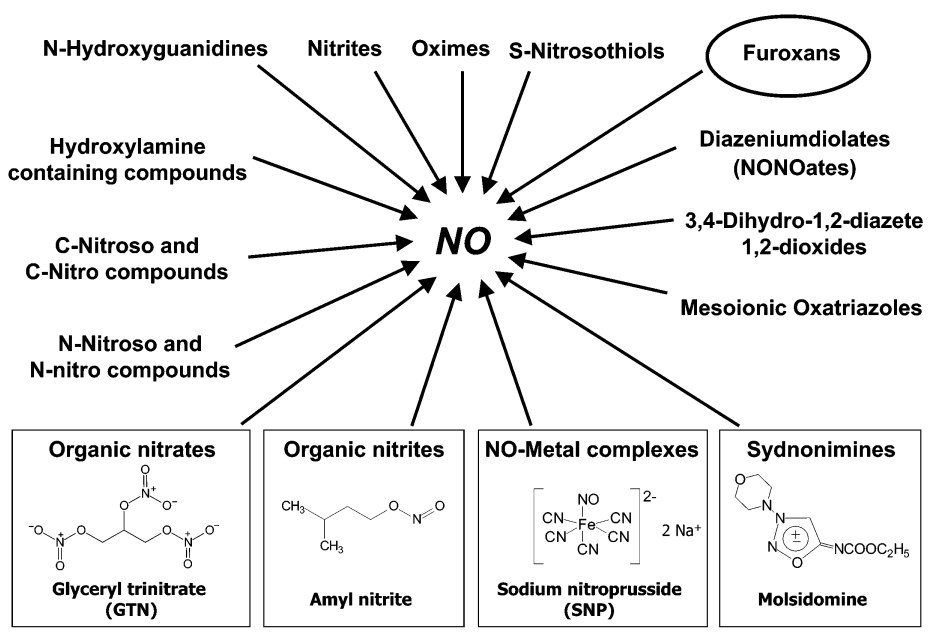

Fig. 2 NO donors.

Some NO donors are currently used for the treatment of certain cardiovascular diseases [4]. The most important among these are the organic nitrates. The prototype of these drugs is glyceryl trinitrate. Other NO donors that have now been in long use are organic esters of nitrous acid and sodium nitroprusside, a complex between $\mathrm{NO}^{\bullet}$ and iron. More recently, molsidomine, a sydnonimine, has also become available. All these drugs may be considered accidental NO donors, since they were introduced before it was clear that nitric oxide is involved in their action mechanism. Two other important classes of NO donors are nitrosothiols and NONOates. These products are not clinically used, but are useful pharmacological tools. This is because they are able to release $\mathrm{NO}^{\bullet}$ in a quantitative manner, when dissolved in physiological solution (eqs. 1 and 2). The half-lives of these products are strongly dependent on their structures. In the case of nitrosothiols, the decomposition to $\mathrm{NO}^{\bullet}$ is influenced by the presence 
of transition-metal ions, in particular $\mathrm{Cu}^{+}$. Again, the sensitivity of a thiol to this catalysis is dependent on its structure [5].

$$
\begin{aligned}
& 2 \mathrm{RSNO} \rightarrow \mathrm{RSSR}+2 \mathrm{NO}^{\bullet} \\
& \mathrm{R}^{\prime} \mathrm{R}^{\prime \prime} \mathrm{NN}\left(\mathrm{O}^{-}\right) \mathrm{NO} \stackrel{\mathrm{H}^{+}}{\rightarrow} \mathrm{R}^{\prime} \mathrm{R}^{\prime \prime} \mathrm{NH}+2 \mathrm{NO}^{\bullet}
\end{aligned}
$$

\section{FUROXANS AS NO DONORS}

Among NO donors, derivatives of a minor heterocycle system, the furoxan ring, are also included (Fig. 3).

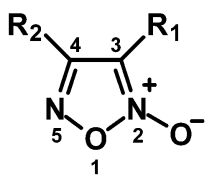

Fig. 3 General structure of furoxans.

Furoxan is 1,2,5-oxadiazole 2-oxide and is part of the chemical history of the University of Turin, since Prof. Ponzio, at the Chemical Institute, studied it for over 40 years, during the first half of the $20^{\text {th }}$ century [6]. Early reports showing that furoxan derivatives can mimic some of physiological actions of nitric oxide relate to the in vitro antiaggregatory and vasodilating activity of a series of isomer methyl-arylsulfonylfuroxans [7,8]. 4-Methyl-3-phenylsulfonylfuroxan (1), one of the most active products of the series, has been closely examined for its biochemical pharmacology [9]. It showed typical behavior of a NO donor. Its ability to inhibit platelet aggregation induced by arachidonic acid (AA) in human plasma is reversed by the presence of $\mathrm{HbO}_{2}{ }^{++}$, a well-known scavenger of nitric oxide. In addition, it increases the cyclic GMP (cGMP) concentration in human platelets in a dose-dependent man-

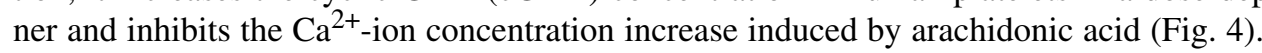
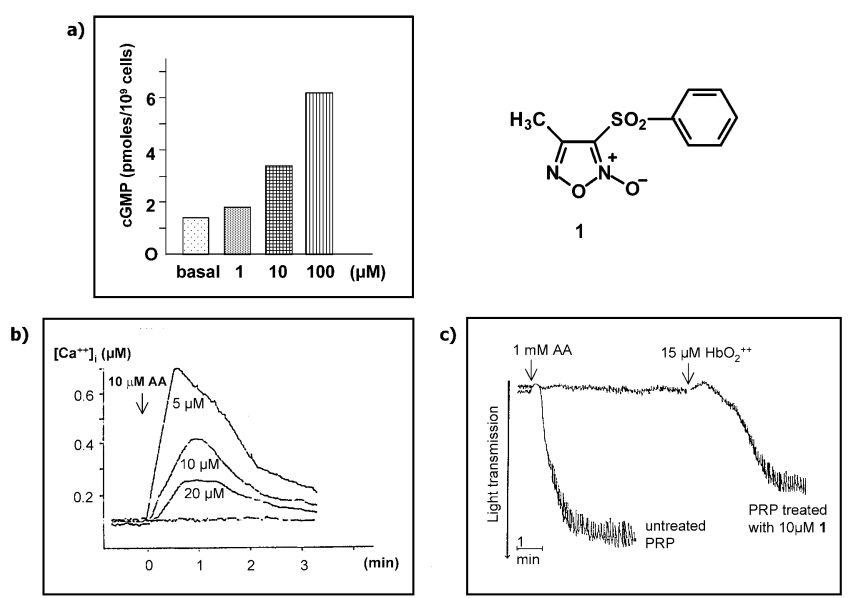

Fig. 4 Biochemical characterization of 1 in human platelets: (a) cGMP accumulation; (b) inhibition of AA-induced increase in $\left[\mathrm{Ca}^{2+}\right]$; (c) inhibition of AA-induced platelets aggregation (adapted from ref. [9]).

During the same period, a paper by Feelisch et al. showed that furoxans release NO when incubated in physiological solution in the presence of thiols [10]. Among the reaction products, the group isolated dioxime derivatives, which are well-known reduction products of furoxans under the action of 
thiols, together with nitrite and, in smaller amounts, nitrate, which are the oxidation products of nitric oxide in aerobic water solution. They also evidenced the presence of nitrosothiols. From these results, they proposed a reasonable mechanism for NO production (Fig. 5).

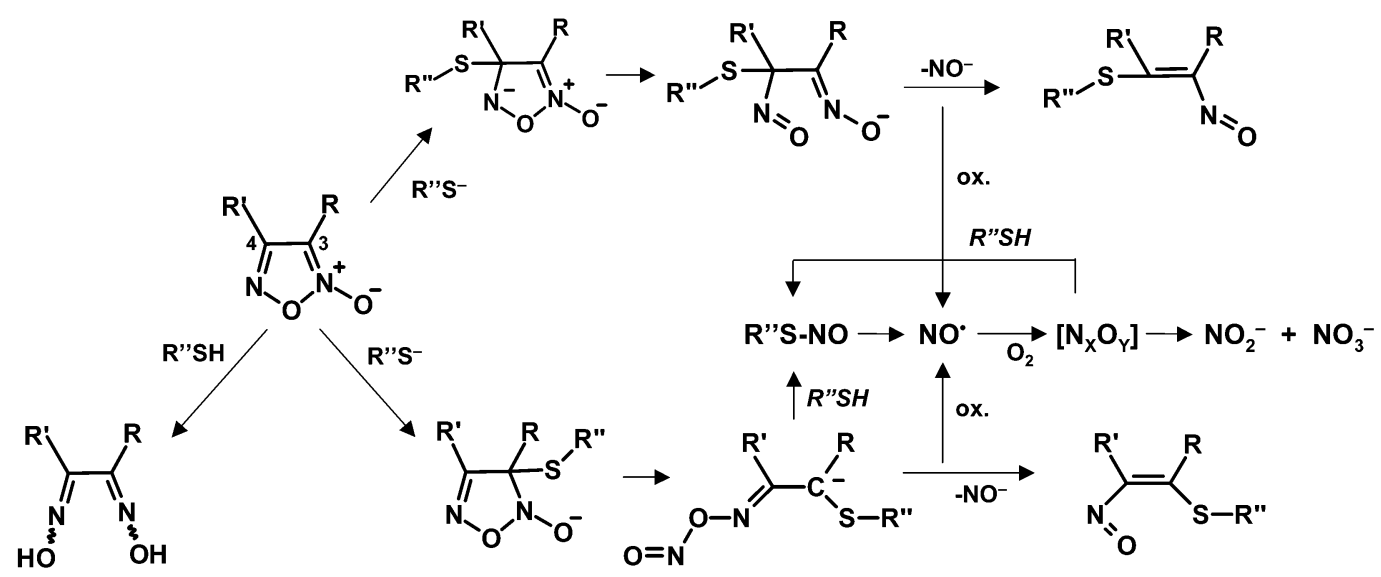

Fig. 5 NO release from furoxan in physiological solution under the action of thiols (adapted from ref. [10]).

This mechanism implies nucleophilic attack of the thiolate group at the 4- and/or at the 3-position of the furoxan ring. In the first case, the resulting tetrahedral intermediate opens to a nitroso derivative, which could produce nitroxyl anion. This redox form is oxidated to nitric oxide that, in its turn, in the presence of oxygen produces nitrite and nitrate. The interaction of oxygenated nitrogen species, formed during this transformation, with thiols could justify the production of nitrosothiols. The attack of thiolate at the 3-position presumably produces similar transformations with the sole difference that one of the intermediates might generate nitrosothiols directly by interaction with thiols. The reaction of 4-phenyl-3-furoxancarbonitrile with an excess of thiophenol in a $7.4 \mathrm{pH}$ buffer phosphate/ethanol mixture affords, among the final products, nitrite and 5-amino-3-phenyl-4-phenylthioisoxazole in comparable yields [11]. This suggests that, at least in this case, the attack of thiolate anion preferentially occurs at the 3-position. In conclusion, NO release from furoxan in physiological solution and in the presence of thiols, is a complex process that probably involves more than one redox form of NO. Not only thiol-induced, but also/or enzymatic NO generation could occur in tissue bioactivation of furoxans. For example, the furoxancarbonamide derivative C92-4679 (Fig. 3; $\mathrm{R}_{1}=\mathrm{C}_{6} \mathrm{H}_{5}, \mathrm{R}_{2}=$ CONHPyrid3 -yl) elicits a concentration-dependent relaxation of femoral artery segments of rabbits precontracted with phenylephrine. When the segments are preincubated with proadifen, an inhibitor of cytochrome $\mathrm{P} 450$, there is a significant rightward shift of the concentration-response curve. This could suggest the involvement of this enzyme in the bioactivation of the product [12]. By contrast, this enzyme does not seem to be involved in the NO release of other furoxancarbonamides, such as CAS-1609 (Fig. 3; $\mathrm{R}_{1}=$ $\mathrm{CONH}_{2}, \mathrm{R}_{2}=\mathrm{CH}_{2} \mathrm{OH}$ ): with this product, the second curve does not undergo significant rightward shift.

A number of water-soluble furoxans, bearing as substituent a chain containing an amino function partially protonated at physiological $\mathrm{pH}$, were systematically studied for their NO-dependent vasodilating properties [13]. All these products dilate rat aorta strips precontracted with noradrenaline in a concentration-dependent manner. Their potencies $\left(\mathrm{EC}_{50}\right)$ are to a great extent modulated within the series. The most potent derivatives are those bearing an aminoalkylsulfonyl group, in particular, 3-positioned on the ring. When the experiments were repeated in the presence of $\mathrm{HbO}_{2}{ }^{++}$, the potency decreased. This clearly indicates the involvement of NO in the vasodilating action. Additional proof of 
this involvement derives from the linear correlation between the log of the potency and the log of the molar concentration of each compound releasing a fixed amount of $\mathrm{NO}$ in $1 \mathrm{~min}\left(\mathrm{C}_{\mathrm{NO}}^{1 \mathrm{~min}}\right)$ (Fig. 6).

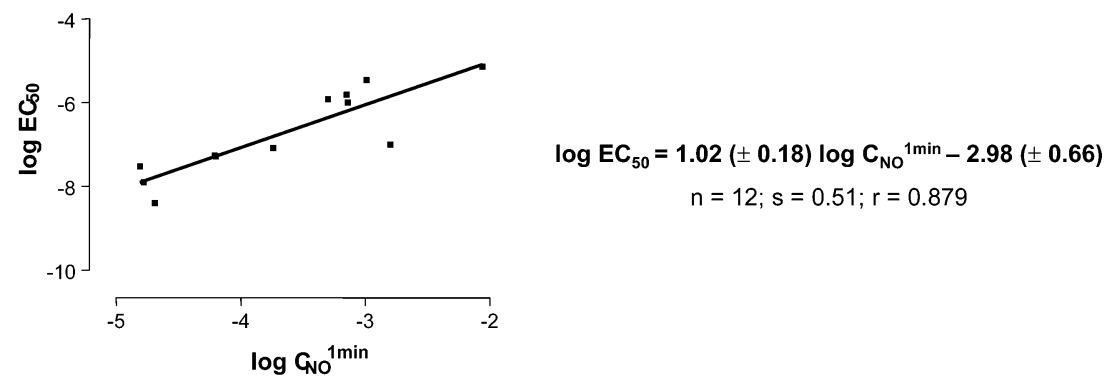

Fig. 6 Correlation between the $\log$ of the vasodilating potency $\left(\mathrm{EC}_{50}\right)$ and the $\log$ of $\left(\mathrm{C}_{\mathrm{NO}}{ }^{1 \mathrm{~min}}\right)$.

The vasodilatory properties of a number of these products have been studied in vivo at the laboratories of Hoechst Company, in Frankfort. One of the best results was obtained with the product G95-6527 (Fig. 3; $\left.\mathrm{R}_{1}=\mathrm{S}-\left(\mathrm{CH}_{2}\right)_{2}-\mathrm{N}\left(\mathrm{CH}_{3}\right)_{2}, \mathrm{R}_{2}=\mathrm{C}_{6} \mathrm{H}_{5}\right)$. It induced a decrease of both the systolic $(\triangle \mathrm{BPs})$ and diastolic blood pressure $(\triangle \mathrm{BPd})$, when administered at $3 \mathrm{mg} / \mathrm{kg}$ by intraduodenal route (i.d.) to anesthetized pig. The onset of the action is slow, and the maximum effect is reached after $30 \mathrm{~min}$. The action lasts for over $2 \mathrm{~h}$. The effect on the left ventricular end diastolic pressure ( $\triangle$ LVEDP) is weak and is not clearly correlated with the decrease of systolic blood pressure. By contrast, when the furoxan G95-5376 (Fig. 3; $\left.\mathrm{R}_{1}=\mathrm{S}-\left(\mathrm{CH}_{2}\right)_{2}-\mathrm{N}\left(\mathrm{CH}_{3}\right)_{2}, \mathrm{R}_{2}=\mathrm{SO}_{2}-\mathrm{C}_{6} \mathrm{H}_{5}\right)$ was administered to anesthetized pig at $0.3 \mathrm{mg} / \mathrm{kg}$ by the intravenous route (i.v.) correlation between the decrease of $\triangle \mathrm{BPs}$ and $\triangle$ LVEDP was close (Fig. 7).

a)

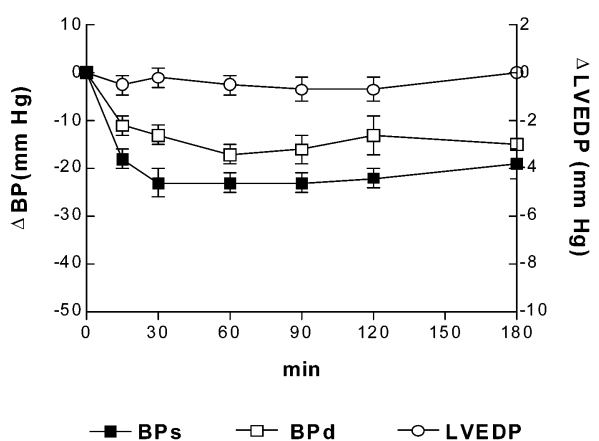

b)

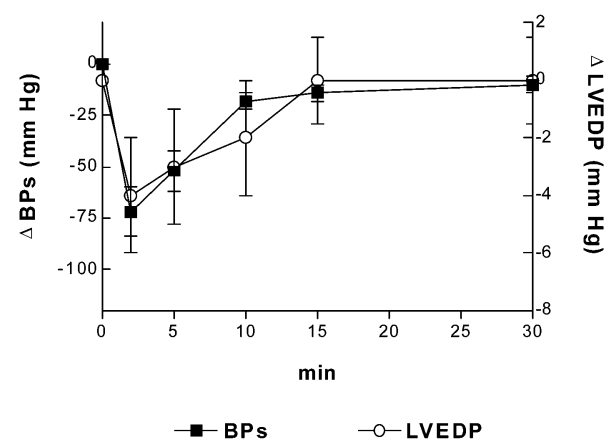

Fig. 7 (a) Hemodynamic profile of G95-6527; (b) Hemodynamic profile of G95-5376 (P. Martorana, personal communication).

Some pharmaceutical companies were interested in furoxans as potential cardiovascular drugs, especially Cassella-Hoechst, which has studied hundreds of derivatives of this heterocycle; among them, CAS 1609 emerged as a candidate for clinical investigations [14]. This product displayed quite a good hemodynamic profile in the anesthetized dog, when administered by the intravenous route. It is a potent long-lasting, orally active vasodilator, and, remarkably, it is devoid of tolerance (Fig. 8). It remained a potent vasodilator when administered orally to conscious dog for a period of five days. The lack of tolerance appears to be an important property of vasodilatory furoxan derivatives $[12,14,15]$. Unfortunately, CAS 1609 has mutagenic activity, and this precluded any further clinical study. Potential 
$\rightarrow$ C AS $1609(2 \times 0.5 \mathrm{mg} / \mathrm{kg})$

d ay 1

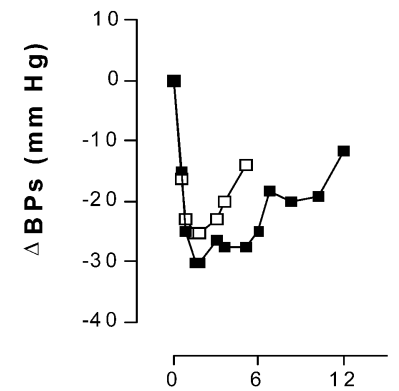

day 3

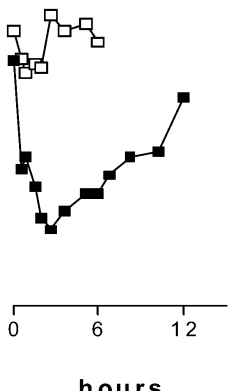

$\multimap$ IS MN $(3 \times 10 \mathrm{mg} / \mathrm{kg})$

da y 5

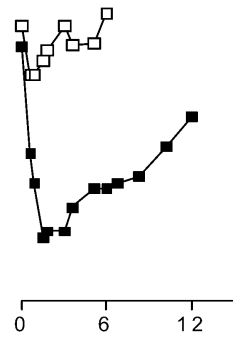

Fig. 8 In vivo tolerance study of CAS 1609 and isosorbide mononitrate (ISMN) (K. Schönafinger, personal communication).

mutagenic properties of furoxans, as well as of all other NO donors, is a problem still in need of additional investigations.

\section{FUROXAN/DRUG HYBRIDS}

A recent innovative development in NO donor drug research is the design of NO donor/drug hybrids [2]. This approach is conduced either by joining a current drug with a NO donor moiety directly or through an appropriate spacer or alternatively by fusing only one part of the drug with the NO donor substructure. The resulting new drug may be endowed with dual action, that of the parent drug and that of the NO-donor moiety. The prototype of these products is nicorandil, a drug used clinically in the management of a number of cardiovascular diseases. In this product, the nicotincarbonamide $\mathrm{K}^{+}$-channel activator is linked to a vasodilator nitrooxy function by an aliphatic bridge. The main advantage of a "hybrid" over the concomitant administration of the two individual active principles is that the single entity is absorbed and excreted at one rate in a given subject, thus maximizing the chance of a balanced profile during the entire course of drug action. A number of currently used drugs have been hybridized with NO donor moieties, in particular, nitrooxy and nitrosothiol functions. NO-NSAIDs are typical examples [16]. These hybrids retain the anti-inflammatory and anti-aggregatory effects of the parent drugs, but they appear to be devoid of gastrotoxicity owing to the presence of the NO donor moiety. Some of them are in clinical development.

The furoxan system has also been used in this approach. Many drugs have been linked or fused with furoxan substructures to obtain NO donor drugs. They include $\alpha_{1}$-antagonists, $\beta_{1}$-antagonists, $\mathrm{K}^{+}$-channel activators, $\mathrm{Ca}^{2+}$-channel blockers, NSAIDs, and $\mathrm{H}_{3}$ - and $\mathrm{H}_{2}$-antagonists. All these $\mathrm{NO}$ donor hybrids were reviewed [2,17]. More recently, NO donor furoxans were also joined to 1,4-dihydropyridine $\mathrm{Ca}^{2+}$-channel activators [18], as well as to the REC15/2739, a uroselective $\alpha_{1}$-antagonist [19], and to the rabeprazole, a potent inhibitor of $\mathrm{H}^{+} / \mathrm{K}^{+}$-ATPase enzyme [20]. One of the problems that must be addressed when working with hybrid drugs is their balance. Generally speaking, in an A-B hybrid the biological properties of the two pharmacophoric groups A and B must be present in an appropriate balance, namely, the properties of one group must not prevail over those of the other. The furoxan ring is quite a flexible tool to reach this goal since its NO-releasing properties and, consequently, its NO-dependent pharmacological activities can be modulated depending on the nature of the substituent at the ring. For example, when 3-methylfuroxan-4-yloxymethyl, a feeble NO donor moiety, was joined to the 4-phenyl-1,4-dihydropyridine substructure (4-Ph-1,4-DHP) a product with prevalent $\mathrm{Ca}^{2+}$-blocker properties was obtained (der. 2; Fig. 9) [21]. 


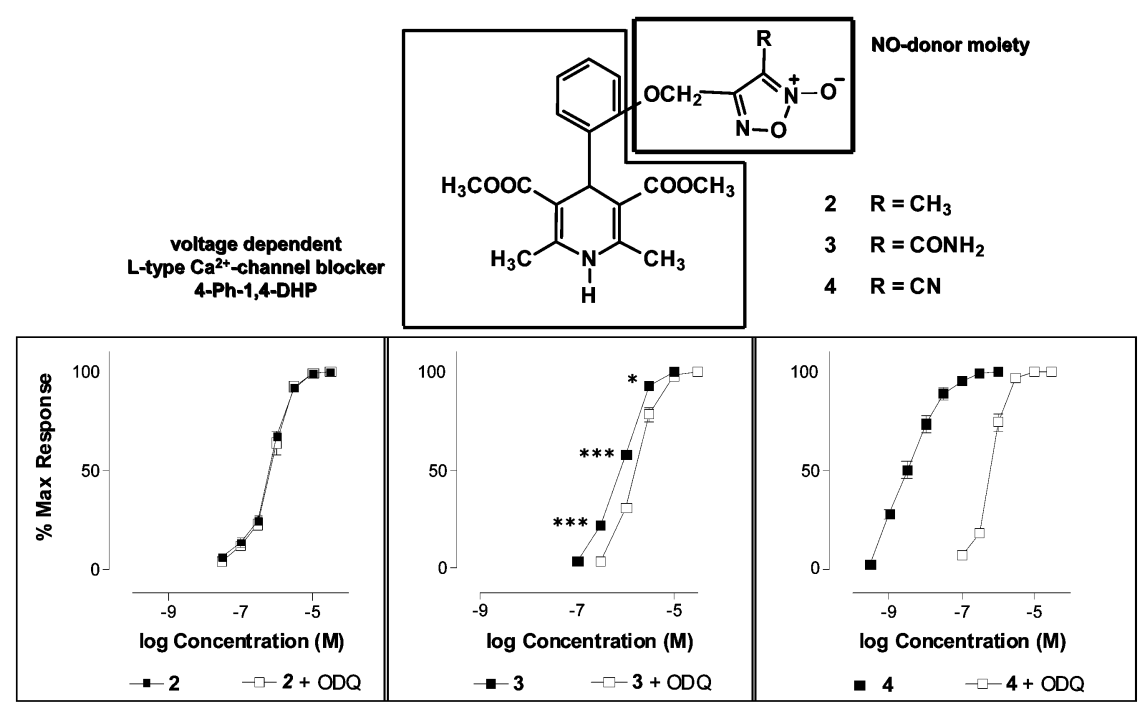

Fig. 9 In vitro vasodilating activity of derivatives $\mathbf{2 - 4}$ in the absence and in the presence of ODQ.

In fact, this product was found to dilate rat aorta strips precontracted with a solution of $\mathrm{K}^{+}$ions in a dose-dependent manner. When the experiments were repeated in the presence of ODQ, a product able to inactivate the sGC and consequently to block the NO signal transduction, the new dose-response curve overlapped the previous one. By contrast, using the strong NO donor 3-cyanofuroxan-4yloxymethyl substructure, this second curve was shifted considerably to the right. Consequently, the resulting product $\mathbf{4}$ behaves principally as a NO-dependent vasodilator. Finally, using the moderate NO donor 3-carbamoylfuroxan-4-yloxymethyl group, this second curve was only partially shifted rightwards, and consequently the resulting product $\mathbf{3}$ displayed vasodilatory activity dependent both on its calcium channel blocker and its NO donor properties, in a wide range of concentrations. A similar strategy was followed to balance in vivo a series of $\mathrm{NO}$ donor $\mathrm{H}_{2}$-antagonists [22]. These products were designed to produce new $\mathrm{H}_{2}$-antagonists endowed with gastroprotective properties dependent on their ability to release NO. They were obtained by joining lamtidine and tiotidine pharmacophores to several NO donor moieties, including nitrooxy, nitrosothiol, and substituted furoxan moieties. The derivative $\mathbf{5}$ emerged as the best balanced hybrid. When administered intravenous to anesthetized rat, it inhibited the acid secretion induced by hystamine in a dose-dependent manner and, when administered by the intragastric route, it displayed dose-dependent gastroprotective properties against lesions induced by $0.6 \mathrm{~N} \mathrm{HCl}$ (Fig. 10). The parent compound, deprived of the furoxan moiety, was a more potent inhibitor of acid secretion, but lacked gastrospearing activity. 

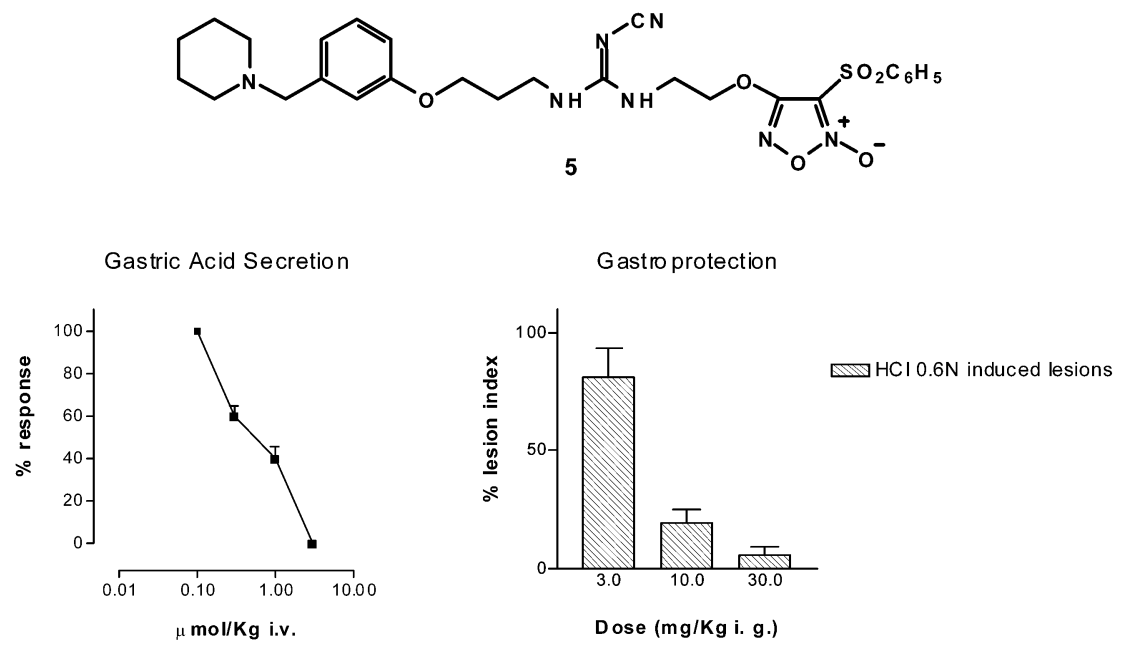

Fig. 10 Gastric acid secretion and gastroprotection of derivative 5 .

Both old and recent reports $[6,17,23]$ have been published claiming antihelmintic, antitumoral, and antimicrobial activities for some furoxan derivatives. It is possible that all these biological actions are at least partly dependent on the capacity of the products to release NO. It could be interesting for the furoxan pharmacochemistry to address this aspect.

\section{CONCLUSIONS}

Furoxan derivatives are stable compounds capable of producing NO in physiological solution, under the action of thiol cofactors. Their NO release mechanism both in vitro and in vivo still requires additional investigations as their metabolism and toxicity. These products display typical NO-dependent activities both in vitro and in vivo, in particular, antiplatelet and vasodilatory properties. Remarkably, they are vasodilators devoid of any tolerance effect in vivo. The possibility of modulating NO release by changing the substituent on the ring makes furoxan derivatives flexible tools in designing NO donor/drug hybrids. Whether other as yet little studied biological activities of furoxans, such as their antiparasite, antimicrobial, and antitumoral effects, are NO-dependent, is a matter still to be explored.

\section{REFERENCES}

1. J. F. Kerwin, Jr., J. R. Lancaster, Jr., P. L. Feldman. J. Med. Chem. 38, 4343-4362 (1995).

2. P. G. Wang, M. Xian, X. Tang, X. Wu, Z. Wen, T. Cai, A. J. Janczuk. Chem. Rev. 102, 1091-1134 (2002).

3. S. A. Lipton, J. S. Stamler, D. J. Singel. Nature 367, 28 (1994).

4. J. D. Horowitz. "Nitrovasodilators", in Nitric Oxide and the Cardiovascular System, J. Loscalzo and J. A. Vita (Eds.), pp. 383-409, Humana Press, Totowa (2000).

5. I. L. Megson. Drugs Future 25, 701-715 (2000).

6. A. Gasco and A. J. Boulton. Adv. Hetrocycl. Chem. 29, 251-340 (1981).

7. R. Calvino, R. Fruttero, D. Ghigo, A. Bosia, G. P. Pescarmona, A. Gasco. J. Med. Chem. 35, 3296-3300 (1992).

8. R. Ferioli, A. Fazzini, G. C. Folco, R. Fruttero, R. Calvino, A. Gasco, S. Bongrani, M. Civelli. Pharmacol. Res. 28, 203-212 (1993).

9. D. Ghigo, R. Heller, R. Calvino, P. Alessio, R. Fruttero, A. Gasco, A. Bosia, G. P. Pescarmona. Biochem. Pharmacol. 43, 1281-1288 (1992). 
10. M. Feelisch, F. Schönafinger, E. Noack. Biochem. Pharmacol. 44, 1149-1157 (1992).

11. C. Medana, G. Ermondi, R. Fruttero, A. Di Stilo, C. Ferretti, A. Gasco. J. Med. Chem. 37, 4412-4416 (1994).

12. M. Hecker, W. Vorhoff, A. T. Bara, P. I. Mordvintcev, R. Busse. Naunyn-Schmiedeberg's Arch. Pharmacol. 351, 426-432 (1995).

13. G. Sorba, C. Medana, R. Fruttero, C. Cena, A. Di Stilo, U. Galli, A. Gasco. J. Med. Chem. 40, 463-469 (1997); 40, 2288 (1997).

14. H. Bohn, J. Brendel, P. A. Martorana, K. Schönafinger. Br. J. Pharmacol. 114, 1605-1612 (1995).

15. M. Civelli, M. Giossi, P. Caruso, R. Razzetti, M. Bergamaschi, S. Bongrani, A. Gasco. Br. J. Pharmacol. 118, 923-928 (1996).

16. U. K. Bandarage and D. R. Janero. Mini Rev. Med. Chem. 1, 57-70 (2001).

17. H. Cerecetto and W. Porcal. Mini Rev. Med. Chem. (2004). In press.

18. D. Vo, J. T. Nguyen, C. A. McEwen, R. Shan, E. E. Knaus. Drug Dev. Res. 56, 1-16 (2002).

19. D. Boschi, G. C. Tron, A. Di Stilo, R. Fruttero, A. Gasco, E. Poggesi, G. Motta, A. Leonardi. J. Med. Chem. 46, 3756-3765 (2003).

20. G. Sorba, U. Galli, C. Cena, R. Fruttero, A. Gasco, G. Morini, M. Adami, G. Coruzzi, M. I. Brenciaglia, F. Dubini. ChemBioChem 4, 899-903 (2003).

21. A. Di Stilo, S. Visentin, C. Cena, A. M. Gasco, G. Ermondi, A. Gasco. J. Med. Chem. 41, 5393-5401 (1998).

22. M. Bertinaria, G. Sorba, C. Medana, C. Cena, M. Adami, G. Morini, C. Pozzoli, G. Coruzzi, A. Gasco. Helv. Chim. Acta 83, 287-299 (2000).

23. L. I. Khmel'nitskii, S. S. Novikov, T. I. Godovikova. Chemistry of Furoxans: Reactions and Applications $2^{\text {nd }}$ ed., M. Nauka, in Russian (1996). 